\title{
Contribuciones literarias, biográficas y autoetnográficas a la antropología médica en España: el caso catalán
}

\author{
Literary, biographic and autoethnographic \\ contributions in Spanish medical anthropology: the \\ case of Catalonia
}

Elisa Alegre-Agís ${ }^{1}$, Isabella Riccò ${ }^{2}$

'Doctoranda en Antropología y Comunicación. Becaria de Investigación, Universitat Rovira i Virgili, Tarragona, España. $\triangle$ iD

${ }^{2}$ Magíster en Antropología Cultural y Etnología. Becaria de investigación, Universitat Rovira i Virgili, Tarragona, España. $\triangle$ iD
RESUMEN El método autoetnográfico ha sido un importante aporte al desarrollo de la antropología médica en España. En la primera parte de este artículo, se exploran y revisan documentos habitualmente clasificados como literatura y autobiografías, vinculados a los procesos de salud-enfermedad-atención y publicados antes de 1980, cuyo paradigma es el diario de Ramona Via, Com neixen els Catalans, publicado en 1972. La segunda parte se enfoca en las contribuciones desarrolladas desde la década de 1980, a partir del concepto de autoetnografía, cuyos objetos son el cuerpo, la salud y la enfermedad a partir de la experiencia etnográfica subjetiva. A diferencia del primer periodo, éste se caracteriza por el surgimiento de autores antropólogos que han impulsado el desarrollo de este método legitimado desde la escuela de Tarragona, y concretizado en el primer congreso español de autoetnografía en 2015.

PALABRAS CLAVES Antropología Médica; Metodología; Etnografía; España.

ABSTRACT The autoethnographic method has been an important contribution to the development of medical anthropology in Spain. This article first reviews and explores documents published before 1980 that are usually classified as literature and autobiography and are linked to the health-disease-care process, a paradigmatic example of which is Ramona Via's diary Com neixen els Catalans [How Catalans are born] published in 1972. The second part of the article is focused on contributions carried out since the 1980s using the concept of autoethnography, which have as their object the body, health and illness based on a subjective ethnographic experience. This period, unlike the first, is characterized by the emergence of anthropologist authors who have promoted the development of this method, legitimized by the Tarragona School and substantialized in the first Spanish conference of autoethnography in 2015.

KEY WORDS Medical Anthropology; Methodology; Ethnography; Spain. 


\section{INTRODUCCIÓN}

La autoetnografía, como método o género literario, es hoy relativamente frecuente, pero aún controvertida para la antropología más ortodoxa; supone una forma de experimentar el trabajo de campo, la escritura y la potestad del autor desde un margen que permite alejarse de la hipocondríaca pretensión de objetividad en las ciencias sociales. Así, podemos acercarnos a una concepción más compleja de las realidades en el marco del "conocimiento situado"(1), una construcción teórica que nos sirve para debatir cómo se desarrolla ese conocimiento cuando el rol del etnógrafo juega un papel fundamental. La autoetnografía entreteje al autor y su experiencia vivida en clave analítica para una mejor comprensión del tema que se investiga. Así, este método pone al etnógrafo en la encrucijada de protagonizar o de formar parte del vaivén entre la experiencia cercana y la experiencia distante, un ejercicio dinámico en el que se buscan los límites metodológicos y se abren nuevos debates sobre lo objetivo y lo subjetivo que, a veces, parecían estar superados ${ }^{(2)}$.

Este artículo reúne las autobiografías y autoetnografías más representativas en el marco de la antropología médica, producidas en el Estado español, especialmente en Cataluña. En una primera parte, seleccionamos algunas obras anteriores a los años ochenta, textos personales o autobiográficos, diarios y dietarios con un gran valor etnográfico que representan la tradición de este género en el territorio. Posteriormente, pasaremos a la década de 1980 como punto de inflexión y entrada álgida de la autoetnografía como método y género narrativo específico; obras que, por su contenido, están especialmente vinculadas a los procesos de salud, enfermedad y atención. En particular, veremos los autores más representativos de la llamada "Escuela de Etnografía de Tarragona", pionera en la metodología autoetnográfica, y espacio legitimado desde hace más de veinticinco años en el desarrollo de este género.

\section{De la narrativa al método: la autoetnografía como género y su representación en España}

Entre el ademán positivista de ver al "otro" con extrañeza y el ánimo por el going native, posiblemente Malinowski nos haya dejado una de las más tremendas paradojas de nuestra disciplina. Su libro por excelencia, Los argonautas del Pacífico occidental(3) y su Diario de campo en Melanesia(4), publicado tras su muerte, son la mayor materialización de dicha paradoja. Quizá Malinowski haya sido uno de los primeros en poner de relieve la narrativa autoetnográfica sin saberlo, y sin quererlo, ya que su Diario no fue escrito para ser publicado. Sin embargo, la "no intencionalidad" no lo exime de cualidades relacionadas con la autoetnografía. Lo que su diario pone de manifiesto es una pieza clave del hacer etnográfico: la relación entre el investigador, su experiencia y la cultura estudiada. Según Ellis ${ }^{(5)}$ y Richardson ${ }^{(6)}$, la autoetnografía es la investigación, escritura y método que conectan lo autobiográfico y personal a lo cultural y social, es una exploración entre el yo introspectivo y los descriptores sociales y culturales ${ }^{(7,8)}$. Desde esta perspectiva, si Los argonautas y su Diario hubieran dialogado en un mismo texto, probablemente, hubiera surgido una estupenda autoetnografía.

Este género, desde una perspectiva epistemológica, da cuenta de las realidades en las que vive una persona ${ }^{(9)}$, relatos que solo encuentran sentido dentro del contexto social, cultural y político en el que la comprensión del sujeto es sociológica, antropológica e histórica ${ }^{(10)}$. Desde este paradigma seleccionamos las obras que vamos a explorar en este artículo; aquellas que, por su contenido y su forma, conectan la experiencia de los autores con el contexto en el que se escriben. Los textos escogidos plantean problemáticas diversas: las complejidades del cuerpo, las relaciones con el sistema médico, el pluralismo asistencial, la exclusión social o marginación como encuentro con la vulnerabilidad y la militancia, el ser académico y enfermo crónico, los problemas relacionales con el entorno más cercano y los cuidadores, 
el vivir en contextos dictatoriales, en guerra o posguerra, y el pasar por transiciones democráticas, entre numerosas cosas más. Todo ello tiene como punto común el territorio español, su particularidad histórica, política, cultural y económica pero, sobre todo, estas narraciones comparten los cambios en "el mundo de la vida". La objetividad sigue resultando una arena de discusión cuando abogamos por formas metodológicas o narrativas como la autoetnografía. Su aparición como fenómeno paralelo ha sido recibido básicamente de manera titubeante y crítica; continúa siendo una noción marginal que todavía lucha en las esferas literarias críticas y populares como en la propia antropología ${ }^{(11)}$.

Si las autoetnografías están representadas en la antropología española, conviene puntualizar que, como tal, el uso de ese término es reciente. Por razones que explicitaremos más adelante, este género, a escala internacional y española, ha tenido que ver -aunque no exclusivamente- con temáticas de enfermedad, salud y atención. En los dos repertorios bibliográficos sobre antropología médica en España ${ }^{(12)}$-que incluyen también el folklore médico y las topografías médicas- esta terminología no aparece específicamente, aun cuando ambos incluyen cierto número de referencias a las que puede aplicarse, ex post facto, ese calificativo. Tampoco los recientes estados de la cuestión sobre antropología médica destacan específicamente esa parte de la producción, aunque reseñen la mayor parte de las aportaciones.

\section{LA ANTROPOLOGÍA MÉDICA EN ESPAÑA}

La falta de recursos, así como la inexistencia de un espacio colonial o poscolonial, hizo que la antropología española $-y$ la médica-, centrasen su mirada principalmente en la península, y desarrollen una antropología comúnmente denominada con el término at home ${ }^{(12)}$. Su punto de partida formal fue la publicación de La antropología médica en España ${ }^{(13)}$, compilada por Michael
Kenny y Jesús de Miguel. Se compone de una veintena de contribuciones que "abren la puerta a una antropología aplicada en el medio clínico y discuten los límites del concepto de eficacia simbólica"(12). Por otra parte, se analizan también la relación entre cultura y salud ${ }^{(14,15,16)}$ o salud mental ${ }^{(17)}$, el papel del folklore y de la medicina popular ${ }^{(18,19,20,21,22)}$ en el proceso salud-enfermedad-atención y temas específicos como el parto, la maternidad y la sexualidad ${ }^{(12,23,24,25,26)}$. La autoetnografía comenzará a esbozarse entre los años setenta y los ochenta, durante la Transición democrática, en buena parte, por las limitaciones prácticas de la introducción de la antropología profesional en el país ${ }^{(27)}$, la que Eduardo Menéndez calificó en $1977^{(28)}$ como "modelo antropológico clásico", un modelo internacional de la antropología del siglo XX que no podía implantarse plenamente en España porque casi no existían oportunidades para trabajar, durante un tiempo prolongado, lejos o en ultramar. Incluso, las tesis de doctorado de dos de los padres fundadores, Claudio Esteva, en 1958, y Carmelo Lisón, en 1963, se prepararon respectivamente en el México urbano, donde residía el primero, o en su pueblo natal en Aragón, en el caso del segundo. La segunda generación ${ }^{(29)}$, salvo alguna excepción, desarrolló también su formación de campo muy cerca de su residencia $y$, en muchos casos, en pueblos o lugares en los que la accesibilidad era fácil y económica. Sin embargo, los modelos en que se inspiraron fueron las monografías de antropólogos británicos, estadounidenses y algunos franceses en la Iberia de las décadas de 1940 y 1960, que se inscribían en los cánones del "modelo antropológico clásico"(28) y dejaban poco margen a una escritura personal, puesto que muchos eran las tesis de doctorado de sus autores.

Casi todos los textos fundacionales de la antropología médica catalana son de naturaleza autoetnográfica -como es el caso de Comelles ${ }^{(30)}$, Romaní(31), Allué(32) o DiGiacomo ${ }^{(33)}-$, aunque el yo autoral se disimule tras una escritura formal y académica. Augé y Herzlich ${ }^{(34)}$ apuntaban que escribir sobre salud, enfermedad y atención ponía 
en juego lo personal. Probablemente, cuando encontramos un tema que nos fascina -no solo en materia de salud- y nos dedicamos a él durante años, como es el caso de una tesis doctoral, significa que hay algo más allá de un mero interés académico. Hay una implicación directa, una curiosidad profunda hacia el otro, pero también hacia nosotros mismos y lo que nos rodea. Algunas narrativas personales, previas a 1970, pueden también reconocerse como textos que sirvieron de impulso a un paradigma discursivo que, posteriormente, pudo clarificarse como método "autoetnográfico". Aunque aún predomina un modelo de racionalidad científica, existen cada vez más voces que se posicionan a favor de "otras formas de conocer, marginadas, suprimidas y desacreditadas por la ciencia moderna"(35).

Los textos escogidos aquí tienen un especial valor para la antropología médica, en tanto son reflejo de la interacción entre el individuo y los procesos salud-enfermedadatención en el contexto social y cultural español entre los años sesenta y los noventa. En este encuadre, es posible considerar la autoetnografía como un enfoque alternativo para la generación de conocimientos ${ }^{(11)}$ que ha sabido abrirse espacio, sobre todo en Cataluña, en lo que Oscar Guasch calificó como Escuela de Etnografía de Tarragona ${ }^{(36)}$.

\section{Hacia la autoetnografía como género: Frank y Murphy}

At the will of the body ${ }^{(37)}$, de 1991, y The body silent ${ }^{(38)}$, de 1987 , son dos relatos autobiográficos, a la vez que sumamente reflexivos, y paradigmáticos en antropología médica. El sociólogo Arthur Frank y el antropólogo Robert Murphy nos introducen en su experiencia y sufrimiento vital ligados a enfermedades graves, y logran ser dos obras especialmente valiosas para la autoetnografía.

At the will of the body es una aporte a los estudios del cuerpo y el proceso de enfermar. Si bien no se estructura como un texto etnográfico o antropológico, resulta uno de los escritos autobiográficos más pertinentes para la antropología médica internacional.
El lenguaje distendido, la ironía, el humor y ciertas formas de sarcasmo dotan al texto, simultáneamente, de humanidad y sensibilidad para transmitir con iluminadora claridad las emociones de alguien que es diagnosticado de cáncer. El libro está destinado a personas con experiencias similares en tanto pacientes, aunque el espectro se amplía al resultar útil para cuidadores, profesionales de la salud y la sociedad en general por su abordaje del proceso de enfermar y los procesos diagnóstico-terapéuticos. Frank nos ofrece una aproximación fenomenológica sobre las sensaciones y experiencias corporales cercanas a la muerte, dos procesos que le suceden en poco tiempo, un ataque al corazón a sus treinta y nueve años y un diagnóstico de cáncer a los cuarenta. Los acontecimientos vinculados a ambos episodios se van desarrollando simultáneamente a todo aquello paralelo que es "invisible": la percepción subjetiva de la enfermedad -entendida como illness-, la autopercepción de las transformaciones en la vida cotidiana y las relaciones e implicaciones de las personas cuidadoras. El autor pone en diálogo el modelo explicativo de la biomedicina bajo la idea de disease, y el del paciente bajo la experiencia illness; explica "la enfermedad" como un yo atravesado por el sufrimiento, el dolor y los cambios. La enfermedad no sucede en el cuerpo, sino en uno mismo. Su perspectiva, como paciente activo y curioso en relación con los procesos diagnósticos y terapéuticos, es una aportación teórica, filosófica y fenomenológica necesaria para la antropología médica y las profesiones médicas, aunque no sea un texto académico. Su relato es fundamental para la comprensión de la perspectiva emic de los "pacientes", los padeceres y los malestares. Su narrativa relajada, cercana y sencilla es la clave para exponer cuestiones complejas, prácticamente dilemas ontológicos ligados a la enfermedad, la muerte y la recuperación, con una brillante llaneza y claridad.

The body silent narra la parálisis de su autor, un reconocido antropólogo estadounidense que investigó en Brasil, Nigeria y EE.UU. En 1972, a sus cuarenta y ocho años, Murphy sufrió los primeros síntomas de un 
tumor en la medula espinal que lo condujo a una invalidez permanente. El texto expresa las graves dificultades ligadas a su estado, sin resultar una mera escritura catártica y terapéutica, sino una herramienta para la investigación sobre las consecuencias sociales de la discapacidad. El antropólogo relata su experiencia en las distintas etapas de su enfermedad y su incorporación en la sociedad con una nueva identidad como discapacitado. Su formato analítico apela a la literatura y al análisis de otros autores (Durkheim, Goffman, entre otros) para subrayar las problemáticas vinculadas al proceso salud-enfermedadatención, como el papel del hospital, en tanto institución total, o el prejuicio de la supuesta asexualidad de los minusválidos. Se reflexiona sobre la muerte, el estigma, la lucha por la autonomía y la estética del cuerpo en el mundo occidental. A través de la "narrativa de la experiencia"(39), The body silent acerca el lector a la discapacidad y su profunda conexión con la identidad del cuerpo y las relaciones sociales:

Decimos que la enfermedad y el deterioro son condiciones psicológicas y sociales, así como problemas somáticos, y esto lo vivencié muy de cerca. Las personas con buena salud no valoran su suerte y sus cuerpos; pueden ver, oír, comer, hacer el amor y respirar porque tienen órganos que trabajan y pueden hacer todas esas cosas. Estos órganos y el propio cuerpo son los cimientos sobre los cuales construimos nuestro sentido de quiénes y qué somos, y son los instrumentos a través de los cuales luchamos y creamos la realidad. [Traducción del original: IIIness and impairment, we are told, are psychological and social conditions as well as somatic problems, and this came home to me vividly. People in good health take their lot, and their bodies, for granted; they can see, hear, eat, make love, and breathe because they have working organs that can do all those things. These organs, and the body itself, are among the foundation upon which we build our sense of who and what we are, and they are the instruments through which we grapple with and create reality]. ${ }^{(38)}$

\section{Paradigmas narrativos en Cataluña: textos personales, dietarios y autobiografías}

El quadern gris $^{(40)}$ de Josep Pla es uno de los textos que marca precedente en la narrativa autobiográfica catalana desde el punto de vista del lenguaje y la estructura. Fue publicado, por primera vez, en 1966 y describe la vida del autor desde marzo de 1918 a noviembre de 1919. Si bien es una autobiografía, su formato de dietario relata los acontecimientos derivados del cierre de la Universidad de Barcelona por la epidemia de la "gripe española" y la vuelta de Pla a Palafrugell (Girona), su lugar de origen. El cuaderno está escrito con una frecuencia casi diaria a partir de notas de viajes, descripciones de paisajes, anécdotas y anotaciones de la vida cotidiana. Según Lluis Bonada ${ }^{(41)}$ el dietario es una ficción literaria, redactada posteriormente a los hechos que describe, y esto se percibe en anacronismos e incongruencias al analizar el texto en profundidad. Aun así, El quadern gris puede considerarse una autobiografía legítima "porque se da la imprescindible identidad del autor, el narrador y el personaje" e incluye una amplísima colección de escritos de valor autoetnográfico ${ }^{(40)}$.

El segundo texto imprescindible es La memoria inquieta ${ }^{(42)}$ de Esteban Pinilla de las Heras, un dietario personal publicado póstumamente, que el autor no pudo revisar. Su narrativa alterna el testimonio personal y el análisis sociológico, y congenia un lenguaje descriptivo relajado junto a la delicadeza del académico; versa sobre los años de la Guerra Civil española y la primera etapa del franquismo autárquico. Esta "autobiografía sociológica", como indica su subtítulo, es un dietario dividido en tres etapas diferenciadas por la lógica biográfica. Sin embargo, no deja de presentar una descripción autoetnográfica muy densa sobre el contexto histórico y político en Barcelona, desde 1935 hasta finales de los años cincuenta. 
En tercer lugar, la obra de la comadrona Ramona Via consta de dos diarios en catalán cuyo propósito era, desde el principio, su publicación. Se trata de dos de los escritos autoetnográficos más destacados y de mayor calidad literaria sobre el proceso salud-enfermedad-atención entre el fin de la Guerra Civil y el franquismo en Cataluña. Su primer diario, Nit de reis: diari d'una infermera de 14 anys de $1966^{(43)}$, es un dietario que comienza en 1938, al final de la Guerra Civil española, escrito mientras trabajaba como enfermera en la retaguardia de la Cataluña Republicana. Recoge un periodo especialmente delicado de la historia catalana, conectando lo cotidiano de su profesión como enfermera con lo extraordinario del contexto político.

En Com neixen els catalans de $1972^{(44)}$ nos ofrece un texto-herramienta esencial para comprender el papel de las comadronas en el proceso de medicalización en la Cataluña rural entre 1945 y 1972. El formato de diario distingue su obra de otras narrativas que tienen un relato literario clásico y de estructura casuística. Ramona revisó sus escritos antes de ser publicados, lo que marca la diferencia con relación a otros tipos de escritura "de servicio"(45). En un análisis de la obra, Lina Casadó(46) remarca su importancia al poner de relieve cuestiones como el papel de las comadronas. Por un lado, se las podía considerar como trasmisoras de las prácticas tradicionales $y$, en este sentido, resultaba una figura que se reiteraba en determinadas actitudes y comportamientos que relegaba a las mujeres a una condición subordinada mediante la reproducción del discurso nacional católico pronatalista. Por otro lado, podían tener un papel trasgresor, dado que sus conocimientos sobre el parto, el aborto, la natalidad y la gestación podían facilitar la libertad de elección de la mujer, lo que iba en contra de los principios católicos, piedra angular ideológica de la dictadura franquista. Ambas, visión y práctica se reflejan en Com neixen els catalans, desmintiendo algunas ideas preconcebidas de la época y mostrando una realidad desde el punto de vista emic como profesional.
Finalmente, uno de los fundadores de la antropología catalana, Lluis Mallart publicó en 1992 Sóc fill dels evuzok ${ }^{(47)}$-aunque los hechos narrados suceden en la década de 1960- como una reacción crítica a El antropólogo inocente ${ }^{(48)}$ de 1989. El texto no tiene la estructura de un dietario ni de un diario, aunque la narrativa en lengua catalana enlaza directamente con Pla y Via ${ }^{(49,50)}$, se aleja del catalán clásico literario del siglo $X X$, y resulta mucho más funcional. En la introducción, Mallart explica que el origen de su experiencia en el continente africano está estrictamente vinculado a su compromiso misionero, lo que lo llevó a descubrir la antropología. El texto no se presenta como una monografía etnográfica clásica, sino que recupera una parte de su historia de vida, sus estancias en Camerún entre 1964 y 1970. Allí aparece su pasión por la antropología y "la consiguiente e inevitable renuncia al compromiso misionero" ${ }^{\prime(35)}$. El proceso vivido por el autor fue inverso al que suelen vivir los antropólogos: elegir un tema de investigación y, después de un tiempo, encaminarse en el trabajo de campo. En el caso de Mallart fue el campo "quien" lo convirtió en antropólogo. Este proceso cambió su visión íntima de la religión, y le permitió relativizar el cristianismo y considerarlo un fenómeno local y marginal dentro de un mundo cultural mucho más vasto y rico. La conversión implicaría, además, un cambio radical en su forma de pensar el mundo, el tiempo y el espacio, una forma que nos ha sido culturalmente trasmitida y que no puede cambiarse sin modificar la memoria colectiva. El estudio del sistema social y cultural evuzok se entrelaza con la biografía del misionero. Se entreteje lo social y la experiencia subjetiva enriquecida por diálogos y relatos para una mejor comprensión de esta comunidad. Su experiencia personal le sirve al autor de herramienta para dar consejos metodológicos. Si bien no se trata de un diario autobiográfico, debido a la reorganización y trabajo de edición del texto, Mallart no deja de estar presente y visible a lo largo de toda la narración. 


\section{LA AUTOETNOGRAFÍA Y LA “ESCUELA DE ETNOGRAFÍA DE TARRAGONA"}

La antropología en la ciudad catalana de Tarragona empezó entre 1974 y 1975. Los primeros cursos universitarios de Antropología Médica se realizaron en 1981 en la División VII que dependía de la Universidad de Barcelona, y en 1984 en la Escuela de Enfermería Joan XXIII de Tarragona ${ }^{(12)}$. Se trataba inicialmente de un campus modesto que ofrecía titulaciones generalistas en Química y Filosofía y Letras. Sin embargo, al tratarse de la segunda región metropolitana de Cataluña, después de Barcelona, contar con el principal polígono petroquímico del Estado y ser un destino turístico de primer orden, le permitió el desarrollo y la ampliación de estudios universitarios que, en 1991, dieron lugar a la nueva Universitat Rovira i Virgili. En ese contexto, el surgimiento de la antropología tarraconense fue la consecuencia de una serie de azares y singularidades que han jugado un papel muy significativo en la institucionalización de la disciplina, tanto en Cataluña como en España. Ser el polo de la antropología médica de la península ibérica y de Europa del sur, como veremos, fue producto, en buena medida, de una concepción poco ortodoxa y crítica con relación al "modelo antropológico clásico", en el que las autoetnografías han sido uno de los rasgos de referencia.

\section{Oriol Romaní: entre grifotas, rockers y jipis}

Oriol Romaní(31,51,52), maestro de Oscar Guasch, fue uno de los precursores de la autoetnografía catalana. El antropólogo centró gran parte de su primer trabajo importante, su tesis de licenciatura Drogas y consensus social de la que podemos encontrar un resumen en $1979^{(53)}$, sobre el consumo del hachís entre los "jóvenes radicales urbanos", los estilos de vida de los fumadores y las ideologías alrededor de las drogas. Este colectivo, no solo era bien conocido por el autor, sino que formaba parte de él. Si bien en sus primeros trabajos ${ }^{(54,55,56,57)}$ maneja una escritura academicista y científica -es decir, no expresa de forma explícita su implicación personal en el tema- es con el autoanálisis a lo largo de los años, además de la sistematización de sus propias vivencias, que se acerca cada vez más al modelo autoetnográfico. En 1983 publica uno de sus más importantes trabajos, A tumba abierta: autobiografía de un grifota $^{(58)}$, una de las primeras autobiografías etnográficas escritas en el Estado español, que si bien no es un relato de su propia vida, no dejamos de ver implícita su presencia, en tanto la información a la que el autor accede merece un conocimiento profundo -como él mismo expresa acerca del trinomio necesario para conocer el mundo de las drogas- del contexto, los sujetos y las sustancias. No pasa desapercibida una presencia en escena que va más allá de su implicación como etnógrafo y, sobre todo, de un valor teórico y metodológico en el género de la autobiografía.

A lo largo de su carrera, Romaní ha tenido como eje central la temática de las drogas en el desarrollo de sus investigaciones y numerosas publicaciones. Como Comelles, de quien hablaremos más adelante, hizo falta mucho tiempo para que determinadas participaciones y complicidades en los temas de estudio pudieran ponerse de manifiesto como parte de la metodología de los trabajos. Así, el autor pasará por un periodo de distanciamiento que le permite, posteriormente, hablar desde una cierta subjetividad que habría sido velada, para exponer y exponerse sobre los textos. De esta manera, sus artículos, pensados desde una progresiva experiencia, nos ofrecen el backstage de su recorrido en el mundo de las drogas como investigador y usuario, dotándonos de un conocimiento que ha sido una imprescindible aportación no solo al mundo de la drogas, sino al contexto económico, político, social y a los movimientos contraculturales juveniles que se fueron desencadenando desde los años sesenta en el Estado español y, especialmente, en Barcelona ${ }^{(31)}$. 


\section{Susan DiGiacomo: enfermedad, identidad y política}

Susan DiGiacomo, estadounidense de origen, catalana de "adopción", utilizó la autoetnografía como herramienta para la producción de conocimiento científico. Durante su trabajo de campo doctoral en Barcelona, sobre la construcción de un proyecto nacional catalán en el período de la Transición, le diagnosticaron la enfermedad de Hodgkin, un cáncer que afecta al sistema inmunológico.

En ese momento de su vida, tan importante a nivel personal como académico, se había relacionado con muchos catalanes que, a lo largo del tiempo, se convirtieron en sus amigos, su familia y su soporte durante la enfermedad, tanto así, que la autora acabó compartiendo sus ideales y valores. Antes del diagnóstico se preguntaba si hacer etnografía en Barcelona la estaba convirtiendo en una antropóloga o, "simplemente", en una catalana. Uno de sus primeros textos autoentográficos fue, en su lengua materna Biomedicine as a cultural system: An anthropologist in the kingdom of the sick ${ }^{(59)}$.

Veinticinco años después, reflexionando sobre su obra, descubrió un paralelismo metafórico entre la militancia del pueblo catalán, puesta en práctica mediante la reivindicación de su lengua y su cultura, y la resistencia del paciente al mundo biomédico. Eran dos tipos de hegemonías contra las cuales era un deber hacer sentir la propia voz:

Yo estoy y siempre he estado enormemente agradecida a los médicos que me trataron. Pero lo que no quería era que mi enfermedad estuviera limitada a lo que dice mi historial médico, que la biomedicina se apropiara de mi vivencia de enferma de cáncer y que mi subjetividad quedase reducida al papel sumiso impuesto por el discurso biomédico. Vivir mi enfermedad como mía y en público, narrarla en voz propia -es decir, etnográfica- y ponerla como recurso teórico y práctico delante de un público de antropólogos: mi público.
[Traducción del original: jo estic i sempre he estat enormement agraïda als metges que em van tractar. Però el que no volia era que la meva malaltia fos limitada al que diu el meu historial mèdic, que la biomedicina s'apropiés de la meva vivència de malalta de càncer i que la meva subjectivitat quedés reduïda al paper submís imposat pel discurs biomèdic. Viure la meva malaltia com a meva i en públic, narrar-la en veu pròpia -és a dir, etnogràfica- i posar-la, com a recurs teòric i pràctic, davant d'un públic d'antropòlegs: el meu públic] ${ }^{(33)}$

Gracias al análisis crítico de sus acontecimientos biográficos, llegó a la conclusión que, más allá de sus estudios previos, fue su experiencia de vida en la Barcelona de los años setenta, junto con su inmersión lingüística en el catalán, lo que le permitió vivir su enfermedad en clave etnográfica.

En otros textos ${ }^{(60,61)}$, la antropóloga utiliza la metáfora como fuente de análisis para desentrañar paradojas entre los modelos explicativos de la biomedicina y los modelos explicativos profanos de los "pacientes". Una de sus grandes aportaciones, devenida siempre del análisis autoetnográfico, es la crítica al movimiento "ideológico" de autoayuda y el discurso médico que relaciona el aumento de probabilidades de curarse de enfermedades como el cáncer con la capacidad de "afrontarlas" de un modo positivo; un discurso que ya habría criticado Susan Sontag ${ }^{62}$ y que pone en consonancia a ambas autoras. DiGiacomo pone de relieve la inercia que culpabiliza a los afectados por parte de la medicina, una paradoja que guarda cierta perversidad y que necesitaba, indudablemente, de las exploraciones profundas y acusadas de una paciente/antropóloga como ella.

\section{El relato íntimo de Marta Allué: autoetnografía de pacientes}

Perder la pie/(32) es un texto literario con un lenguaje distendido y sencillo, accesible al público general. Tras veinte años y diez 
ediciones es el best y el long seller más significativo del conjunto de la antropología y de la antropología médica española. Marta Allué, antropóloga social, reconstruye un itinerario personal de un año de duración tras un accidente en el que sufre quemaduras muy graves en el $80 \%$ de su cuerpo. La descripción acusada del episodio es un preludio necesario, ya que permite introducir al lector en lo que será el juego entre el mundo íntimo de Marta, el sistema sanitario (en varios puntos geográficos del territorio español e incluso el estadounidense), los espacios institucionales de la salud pública, la relación con la red social de los "pacientes" y el imaginario cultural respecto a este tipo de procesos terapéuticos. Una de las cuestiones más interesantes es la descripción y análisis de su mundo interior mientras estaba internada sin poder hablar, en una unidad de cuidados intensivos en Madrid.

Marta nos transporta a su cuerpo y su mente, a las emociones y sentimientos que la invadían. Hace del relato una experiencia vivida que nos es difícil comprender como meros observadores (o lectores), aunque logra emocionarnos y desequilibrarnos, introduciéndonos en la escena a través de la "imaginación", elemento con el que convivió durante meses hasta poder comunicarse de modo efectivo. Si en sus inicios el libro se pensó como académico, en el proceso de escritura, dos años después de los acontecimientos (1994-1996), la autora descarta esa posibilidad y se aleja de este lenguaje y de su formalidad. Su experiencia es vivida como paciente sin descartar su condición de antropóloga, sobre todo porque su training etnográfico -muy influenciado por el interaccionismo simbólico-, le es muy útil para organizar sus vivencias y estructurar su relato. Esta posición le posibilitó poner de relieve en el texto su condición de antropóloga, pero también la de paciente, madre, hermana, mujer y de sujeto, convirtiéndose en la "alteridad", en discapacitada. Sacar el texto de los parámetros "científico/académicos" le permitió poner en interacción el binomio paciente/etnógrafa de forma clara y sin necesidad de "neutralizarse". Su posición juega con el mundo interior e íntimo aunque teniendo muy claro qué y cuánto decir-, el mundo privado, las relaciones con el personal médico y su familia, y el mundo público, el funcionamiento clínico y administrativo del hospital.

Su texto es una referencia obligada en muchas formaciones de antropología médica y profesiones sanitarias, y sus lectores suelen ser jóvenes estudiantes, puesto que el libro se propone en los primeros cursos de las carreras. La ventaja de un texto más formalmente literario que académico es que facilita la legibilidad de su tránsito entre lo íntimo, lo privado y lo público en una descripción densa entre lo distante y lo cercano, que pone de relieve la posibilidad de debatir sobre los históricos límites entre ciencia y emoción, objetivo y subjetivo del mundo académico. Después de esta, su primera obra tras el accidente, la autora escribió varios libros sobre el proceso de recuperación ${ }^{(63)}$, la discapacidad ${ }^{(64,65)}$ y los pacientes activos ${ }^{(66)}$.

\section{Mari Luz Esteban y la antropología encarnada: entre cuerpo, género e intimidad}

Tras investigar durante muchos años sobre la imagen del cuerpo en Occidente, la antropóloga vasca Mari Luz Esteban, actualmente profesora en la Euskal Herriko Unibertsitatea y profesora colaboradora de la Maestría de Antropología Médica y Salud Global de la Universitat Rovira i Virgili, publicó un interesante artículo ${ }^{(67)}$ en el que reflexiona sobre su autobiografía corporal. Centrada en el hirsutismo y en las continuas prácticas de régimen que caracterizaron sus años de juventud, explica las consecuencias sociales que estas implicaron. La autora logra aunar el análisis personal con un universo mucho más amplio vinculado a su trayectoria de investigación sobre el cuerpo, el género y la intimidad. En el texto narra cómo "vivía" la percepción de su cuerpo, una percepción que no era neutral, sino que provocaba sentimientos y reacciones en ella (inseguridad, vergüenza) y en los otros (conmiseración, pena, crueldad). 
Articulando su autoetnografía mediante el paradigma del embodiment, Mari Luz Esteban construye una "antropología encarnada" con la que pretende analizar la influencia de la cultura occidental sobre el cuerpo, usándose a sí misma como fuente privilegiada. Su discurso destaca por su sensibilidad, delicadeza y calidad literaria, y nos permite entender de forma clara y evidente cómo el cuerpo no es nunca exclusivamente natural, sino que tiene siempre una connotación social y política, para lo bueno (mediante el empoderamiento), como para lo malo (mediante la discriminación).

\section{Oscar Guasch: la subcultura homosexual}

La sociedad rosa ${ }^{(68)}$, de Oscar Guasch, actualmente profesor en la Universidad de Barcelona, es una etnografía realizada entre 1984 y 1991 derivada de su tesis de licenciatura en zonas de intercambio sexual homosexual, como las áreas de cruising, espacios de muy difícil acceso para personas que no "pertenecen" al colectivo. El acceso a estos espacios para la observación participante, en la que el investigador interactúa con su identidad personal, resultó posible porque no fue reconocido como investigador, sino como un actor más en la escena. El objetivo de su trabajo eran los cambios en la subcultura homosexual vinculados al contexto político español, es decir, el tardofranquismo, la transición democrática y el impacto del sida en la década de 1980. Los elementos autobiográficos no son explícitos en su etnografía, aunque fueron temas de discusión con su director de tesis, Josep Comelles. A finales de los años ochenta, el concepto de autoetnografía era aún intuitivo. Este tipo de narrativa todavía desafiaba la hegemonía de una antropología clásica y ortodoxa. Guasch intenta un discurso "neutro" en su relato que lo desvincularía (personalmente) del debate político e intelectual del movimiento gay de la época.

En el texto adivinamos a Oscar y su biografía, pero solo son reconocibles bajo una gran sutileza que ha de buscarse e interpre- tarse. Cuando Guasch defiende su tesis, todavía era difícil desmarcarse de las fronteras entre ciencia y emoción. Por ello, su narrativa pone de relieve los problemas que existían, y que aún existen, en algunas esferas cuando ponemos en interacción dialéctica identidades etic y emic simultáneamente. La crisis de la objetividad puede revisarse históricamente y, en este sentido, el texto de Guasch es una pieza clarificadora en la que el sujeto debe exponerse de cara a la escritura científica y académica como des-autobiografiado y fuera de toda vinculación con el objeto de estudio.

\section{Comelles: stultifera navis o los yoes autorales}

Stultifera Navis, la locura, el poder y la ciudad ${ }^{(30)}$ es la historia de una metamorfosis. Josep Comelles, médico psiquiatra, fue residente en el Instituto Mental de la Santa Creu de Barcelona durante tres años. En ese periodo descubre la antropología social y entra en otro universo de reflexiones sobre lo que sucede en el "manicomio". Sin embargo, no es sino cuando realiza su tesis de doctorado en antropología ${ }^{(69)}$ que esta metamorfosis se hace consciente y se convierte en una aportación autoetnográfica que no se publicó hasta veinte años más tarde y con una aproximación muy distinta por parte del autor, puesto que este incluye en su obra una autoetnografia de su "autoetnografía" anterior. Hubo que esperar casi veinte años para saber sobre la locura y sus imbricaciones con relaciones de poder dentro de la institución psiquiátrica y con la política barcelonesa durante seis siglos. Por otro lado, nos explica el papel que juega el edificio, en un sentido performativo, con sus connotaciones simbólicas sobre Barcelona. A su vez, la ciudad, con su gente y variopintos periodos políticos, resuena en las dinámicas del Institut Mental.

Comelles fue inicialmente testigo de todo ello como residente y profesional, y también como ciudadano pero, sobre todo, como un joven que descubre y se descubre desde las 
letras, abandonando la profesión psiquiátrica para pasarse al lado oscuro de las ciencias sociales. Su trabajo de campo abarca desde 1973 a 1980, aunque en 1999 retoma la investigación para elaborar una memoria de oposiciones que daría posteriormente lugar a su publicación en 2006 como Stultifera Navis: La locura, el poder y la ciudad ${ }^{(30)}$. Este libro plantea cuestiones metodológicas, algunas ligadas al hacer etnográfico y otras a la autoetnografía específicamente. Pensemos en un joven, residente de un hospital psiquiátrico, que se topa con la antropología y empieza a hacer lo que fundamentalmente hacemos los antropólogos: observar, tomar notas y analizar. Una vez convertido en antropólogo, retoma aquellas notas veinte años después, para continuar con una investigación que complementa con otras metodologías, como el trabajo de archivo en el mismo hospital, que ya no funcionaría como tal. El producto final se encuentra con una voz que es posterior y que pone en relación dialéctica a las dos figuras anteriores (un médico-residente y un antropólogo en construcción). Es, de alguna manera, una autoetnografía a tres voces, un diálogo entre "tres yoes" que nos explica la historia del Institut desde su fundación en 1401 hasta su cierre en 1989. Las tres perspectivas se complementan para mostrarnos un espacio complejo que no se puede desligar de las personas que lo ocupan. Comelles nos deja explorar con sus ojos cada rincón del edificio, sus oficialidades y clandestinidades, sus orgullos y sus vergüenzas. No deja escapar detalle, pero esto lo consigue teniendo una vinculación personal y una trayectoria biográfica con el hospital que lo acompañó en su conformación académica. Su mayor aporte tiene que ver con las posibilidades "temporales" de la etnografía y la posibilidad de hacer caso a la memoria, aunque sea para exponerla en crudo, ponerla en tela de juicio y reflexionar bajo el desfase temporal. Así, la narrativa rompe con el convencionalismo etnográfico y, a su vez, con el método.

\section{CONCLUSIONES}

Uno de los aspectos más interesantes de nuestra disciplina es la fascinación que nos producen nuestros objetos de estudio, una fascinación que históricamente se ha relacionado con lo exótico y que, actualmente, cada vez con más frecuencia, se vincula a la experiencia íntima y subjetiva. A través de estos relatos vemos que el vínculo puede ser aún más fuerte y trascendente. La propia biografía llega a ser una herramienta no solo para escoger uno u otro tema de investigación, sino que también se convierta en el núcleo de la etnografía misma. La dificultad de este tipo de textos duplica al de una etnografía clásica. En las autoetnografías el autor tiene que ser capaz de contar su historia, o que la historia cuente con él para ser más comprensible, pero sin limitarse a la producción de un diario catártico. Las diferentes formas en las que se puede desarrollar el método permiten que el texto se enriquezca a partir de la interacción entre el sujeto que estudia y el objeto de estudio; la autoetnografía nace justamente allí donde se difuminan los límites entre ambas entidades. Cuando esto se consigue, la autoetnografía se convierte en una extraordinaria herramienta de diálogo entre el universo etic y el emic.

La autoetnografía no siempre implica ser el protagonista de la historia, sino que, a veces, nuestra experiencia y nuestro "yo" es necesario como pieza clarificadora. Pensemos en las etnografías at home, en las que el antropólogo no puede desprenderse de la cultura estudiada porque forma parte de ella; en las etnografías Ilamadas "nativas o indígenas" en la que el investigador forma parte además del objeto de estudio; incluso en las etnografías participativas que se construyen a partir de la disolución de la jerarquía entre etnógrafo e informantes. Sea cual fuere el formato en el que se exprese, no podemos negar que el método, como poco, es una fuente de debate metodológico. De hecho, no solo lo es para la antropología médica sino para la antropología en general y otras disciplinas próximas como la sociología, la psicología o 
ciencias de la comunicación, por poner algunos ejemplos ${ }^{(70,71,72)}$.

La mayoría de los textos que hemos seleccionado aquí versan sobre una experiencia que ha producido un cambio en la identidad de sus narradores, sobre todo en casos de enfermedades graves. Retomando a Mari Luz Esteban $^{(67)}$, hacer autoetnografía es un momento en el que se retoma una experiencia de sufrimiento, no solo como antropólogos, sino también como supervivientes, haciendo un análisis que suele partir de una búsqueda de legitimación y de la necesidad de reincorporarse en el mundo con otra identidad.

En los últimos años, la Escuela de Etnografía de Tarragona ha seguido produciendo numerosos artículos y libros con vertientes autoetnográficas, algunas más explícitas que otras, como es el caso de las tesis doctorales de Martín Correa-Urquiza ${ }^{(73)}$, Jaume Esteve ${ }^{(74)}$ e Ilaria Cover ${ }^{(75)}$. El primero relata la construcción de Radio Nikosia, una radio realizada por personas afectadas de problemas de salud mental. Martín Correa-Uquiza, su fundador y aún hoy coordinador, no deja de lado la implicación personal que tiene en la radio, no solo en la práctica cotidiana que lleva a cabo, sino dentro del propio análisis de su desarrollo. Jaume Esteve, por su parte, construye su narrativa alrededor de la comparación de centros públicos de asistencia para drogodependientes con los de Alcohólicos Anónimos, que procede de una experiencia personal directa como participante. Por último, Ilaria Cover dedica un apartado al análisis autoetnográfico sobre sus sueños durante el año de investigación en un hospital psiquiátrico en Alejandría, Egipto.

En noviembre de 2015 la escuela volvió a dar impulso a esta corriente realizando el I Coloquio Internacional de Autoetnografías del Estado Español. En este coloquio se pudo observar la cantidad de antropólogos que, tanto en España como a nivel internacional, trabajan desde la tesitura autoetnográfica. Un espacio que aún es marginal en la disciplina y que es en la escuela de Tarragona donde encuentra uno de los puntos álgidos de legitimación.

\section{REFERENCIAS BIBLIOGRÁFICAS}

1. Haraway D. Simians, cyborgs and women: The reinvention of nature. New York: Routledge; 1991.

2. Geertz C. La interpretación de las culturas. Barcelona: Gedisa Editorial; 2003.

3. Malinowski B. Los argonautas del pacifico occidental: Comercio y aventura entre los indígenas de la Nueva Guinea Melanésica. Barcelona: Editorial Península; 1922.

4. Malinowski B. Diario de Campo en Melanesia. Madrid: Ediciones Jucar; 1989.

5. Ellis C. The ethnographic I: A methodological novel about teaching and doing autoethnography. Walnut Creek: AltaMira; 2004.
6. Richardson L. Writing: A method of inquiry. In: Denzin N, Lincoln Y, (eds.). Collecting and interpreting qualitative materials. Thousand Oaks: Sage; 2003.

7. Reed-Danahay DE. Auto/ethnography. New York: Berg; 1997.

8. Ellis C, Bochner AP. Autoethnography, personal narrative, and personal reflexivity. In: Denzin $\mathrm{N}$, Lincoln $\mathrm{Y}$, (ed.). Handbook of qualitative research. Thousand Oaks: Sage; 2000.

9. Blanco M. Autoetnografía: Una forma narrativa de generación de conocimientos. Andamios Revista de Investigación Social. 2012;9(19):49-74.

10. Velandia Mora MA. De la autobiografía a la autoetnografía como herramienta para el estudio de sí mismo. Bilbao: Universidad del Pais Vasco; 2010. 
11. Valdez CG. Expresión autoetnográfica: consciencia de oposición en las literaturas de los Estados Unidos. Revista de Antropología Social. 2008; 17:73-94

12. Martínez-Hernáez Á, Perdiguero-Gil E, Comelles JM. Genealogía de la antropología médica en España. Revista de Dialectolología y Tradiciones Populares. 2015;70(1):205-233.

13. Kenny M, De Miguel JM. La antropología médica en España. Barcelona: Anagrama; 1980.

14. Prat J, Pujadas JJ, Comelles JM. Sobre el contexto social del enfermar. En: Kenny M, De Miguel JM. La antropología médica en España. Barcelona: Anagrama; 1980. p. 43-68.

15. Kenny M. Valores sociales y salud. En: Kenny M, De Miguel JM. La antropología médica en España. Barcelona: Anagrama; 1980. p. 69-82.

16. Brandes S. Los gitanos y la autoimagen andaluza: análisis psicocultural. En: Kenny $M$, De Miguel JM. La antropología médica en España. Barcelona: Anagrama; 1980. p. 103-119.

17. Fabregat CE. Cultura y salud mental. En: Kenny M, De Miguel JM. La antropología médica en España. Barcelona: Anagrama; 1980. p. 83-102.

18. Tolosana CL. La 'sabia' gallega. En: Kenny M, De Miguel JM. La antropología médica en España. Barcelona: Anagrama; 1980. p. 183-208.

19. Diaz Ojeda MA, Sevilla JL. Patología popular y mal de ojo. En: Kenny M, De Miguel JM. La antropología médica en España. Barcelona: Anagrama; 1980. p. 209-223.

20. McLane MF. Curanderos en Andalucia oriental. En: Kenny M, De Miguel JM. La antropología médica en España. Barcelona: Anagrama; 1980. p. 167-182.

21. Foster G. Relaciones entre la medicina popular española y latinoamericana. En: Kenny M, De Miguel JM. La antropología médica en España. Barcelona: Anagrama; 1980. p. 123-147.

22. Press I. Medicina popular versus medicina científica en Sevilla. En: Kenny M, De Miguel JM. La antropología médica en España. Barcelona: Anagrama; 1980. p. 149-166.

23. Limón Delgado A, Castellote E. La medicina popular en torno al embarazo y el parto a principios de siglo. En: Kenny M, De Miguel JM. La antropología médica en España. Barcelona: Anagrama; 1980. p. 227-248.
24. De Miguel JM. La sociedad estéril: pautas de control de natalidad. En: Kenny M, De Miguel JM. La antropología médica en España. Barcelona: Anagrama; 1980. p. 267-294.

25. Fernández RL. La lactancia materna: progresión de imágenes en su desuso. En: Kenny $M$, De Miguel JM. La antropología médica en España. Barcelona: Anagrama; 1980. p. 295-308.

26. Mulcahy FD. Los valores sexuales de los gitanos: los ritos flamencos. En: Kenny M, De Miguel JM. La antropología médica en España. Barcelona: Anagrama; 1980. p. 309-319.

27. Baztán AA. Historia de la antropología española. Barcelona: Boixareu Universitaria; 1991.

28. Menéndez E. "Nuevos" objetos de estudio de la antropología social. En: Actas de la XV Mesa Redonda de la Sociedad Mexicana de Antropología Social; 1977. p. 75-82.

29. Comelles JM, Prat J. El estado de las antropologías: Antropologías, folclores y nacionalismos en el Estado español. Antropologia. 1992;3(oct):35-61.

30. Comelles JM. Stultifera Navis: La locura el poder y la ciudad. Lleida: Milenio; 2006.

31. Romaní O. Las drogas: sueños y razones. Barcelona: Ariel; 1999.

32. Allué M. Perder la piel. Barcelona: Seix Barral; 1996.

33. DiGiacomo SM. Autobiografia crítica i teoria antropologica. Reflexions a I'entorn de la identitat cultural i professional. Revista d'Etnologia de Catalunya. 2004;(25):124-134.

34. Augé M, Herzlich $C$, (ed.). Le sens du mal: Anthropologie, histoire, sociologie de la maladie. Paris: Editions des Archives Contemporaines; 1983.

35. De Souza B. Crítica de la razón indolente. Bilbao: Editorial Descleé de Brouwer; 2003.

36. Guasch O, Viñuales O. Introducción. En: Sexualidades, diversidad y control social. Barcelona: Bellaterra; 2003. p. 9-18.

37. Frank AW. At the will of the body: Reflections on illness. Boston: Houghton Mifflin; 1991.

38. Murphy RF. The body silent. New York: H. Holt; 1987.

39. Kleinman A. The illness narratives: Suffering, healing, and the human condition. New York: Basic Books; 1988. 
40. Pla J. El cuaderno gris: un dietario. Barcelona: Destino; 1975.

41. Bonada L. L'obra de Josep Pla. Barcelona: Editorial Teide; 1991.

42. Pinillas de las Heras E. La Memoria inquieta: autobiografía sociológica de los años difíciles, 1935-1959. Madrid: CIS; 1996.

43. Via R. Nit de Reis: diari d'una infermera de 14 anys: novel•la. Barcelona: Club Editor; 1966.

44. Via R. Com Neixen els Catalans. Barcelona: Club Editor; 1972.

45. Comelles JM, Brigidi S. Etnografía, realidad y ficción en los médicos y enfermeras en las series de televisión. En: Serena B, (ed.). Cultura, salud, cine y televisión: Recursos audiovisuales en las ciencias de la salud y sociales. Tarragona: Publicacions URV; 2016.

46. Casadó L. 'Com neixen els catalans': La etnografía de Ramona Via en la Cataluña franquista (19451972). In: Perdiguero-Gil E, Comelles JM, (eds.). Medicina y etnografía en Cataluña. Madrid: Consejo Superior de Investigaciones Científicas; 2015.

47. Mallart i Guimerà L. Sóc fill dels Evuzok: La vida d'un antropòleg al Camerun. Barcelona: La Campana; 1992.

48. Barley N. El antropólogo inocente: notas desde una choza de barro. Barcelona: Anagrama; 1989.

49. Comelles JM. El bosc i la pluja. In: Houseman M, Sarró R, (eds.). De I'Àfrica a I'Antropologia: assaigs en homenatge a Lluis Mallart. Barcelona: ICRPC; 2014. p. 119-136.

50. Comelles JM, Brigidi S. La mirada (auto)etnográfica de tres comadronas y su traducción (cinemato)gráfica: Los vericuetos del yo autoral. Revista de Medicina y Cine. 2014;10(4):174-182.

51. Romaní O. La cultura del cannabis treinta años después... unas reflexiones personales. Revista Española de Drogodependencia. 2005;30(3-4):263282.

52. Romaní O. Che ci faccio qui?: Studio degli usi della droga nella Spagna contemporánea: biografia, etnografia e storia. I Fogli di Oriss. 1996;(6):53-102.

53. Romaní O. Droga i consensus social. Comentaris d'Antropologia Cultural. 1979;(1):20-40.

54. Romaní O. Droga i subcultura: una història cultural del 'haix' a Barcelona (1960-1980). Bar- celona: Centre de Publicacions de la Universitat de Barcelona; 1983.

55. Romaní O. Perquè els temps estan canviant... Cultura popular i contracultura. In: Llopart D, Prat J, Prat L, (eds.). La cultura popular a debat. Barcelona: Alta Fulla i Fundació Serveis Cultura Popular; 1985. p. 100-109.

56. Romaní O. La introducción de la droga en la cultura juvenil. Juventud. 1985;17:91-102.

57. Romaní O. Proceso de 'modernización', cultura juvenil y drogas. En: Rodríguez F, (ed.). Comunicación y lenguaje juvenil. Madrid: Fundamentos; 1989. p. 79-98.

58. Romaní O. A tumba abierta: Autobiografía de un grifota. Barcelona: Anagrama; 1983.

59. DiGiacomo SM. Biomedicine as a cultural system. An Anthropologist in the Kingdom of the Sick. In: Baer HA, (ed.). Encounters with biomedicine case studies in medical anthropology. Montreux: Gordoin and Breach; 1987. p. 315-346.

60. DiGiacomo SM. Metaphor as illness: Postmodern dilemmas in the representation of body, mind and disorder. Medical Anthropology. Cross-Cultural Studies in Health and IIIness. 1992;14(1):109-137.

61. DiGiacomo SM. The case: A narrative deconstruction of 'diagnostic delay'. Second Opinion. 1995;20(4):21-35.

62. Sontag S. La enfermedad y sus metáforas: El sida y sus metáforas. Madrid: Debolsillo; 2003.

63. Marta A. La piel curtida. Barcelona: Bellaterra; 2008.

64. Allué M. Discapacitados: La reivindicación de la igualdad en la diferencia. Barcelona: Edicions Bellaterra; 2003.

65. Allué M. El etnógrafo discapacitado: Algunos apuntes sobre la observación de las conductas frente a la discapacidad. Acciones e Investigaciones Sociales. 2002;15:57-70.

66. Allué M. El paciente inquieto: los servicios de atención médica y la ciudadanía. Barcelona: BeIlaterra; 2013.

67. Esteban ML. Antropología encarnada: Antropología desde una misma. Papeles del CEIC. 2004;(12):1-21.

68. Guasch O. La sociedad rosa. Barcelona: Anagrama; 1991. 
69. Comelles JM. Groupes informels, coalitions et factions dans un hôpital psychiatrique. Paris: Ecole des Hautes Etudes en Sciences Sociales; 1979.

70. Samuel-Lajeunesse JF. Nuevas formas literarias para las ciencias sociales: el caso de la autoetnografía. Athenea Digital. 2007;12:262-271.

71. Blanco M. ¿Autobiografía o autoetnografía? Desacatos. 2012;38:169-178.

72. Denzin NK. Autoetnografía analítica o un nuevo déja vu. Astrolabio. 2013;11:207-220.

73. Correa-Urquiza M. Radio Nikosia: la rebelión de los saberes profanos (otras prácticas, otros te- rritorios para la locura). Tarragona: Universitat Rovira i Virgili; 2010.

74. Esteve Blanch J. La dependencia del alcohol: una comparación crítica sobre los tratamientos de dicha dependencia desde modelos biomédicos y espiritualistas. Tarragona: Universitat Rovira i Virgili; 2014.

75. Cover I. Open walls: the experience or psychiatric institutionalization through egyptian women's drawings. Tarragona: Universitat Rovira i Virgili; 2016.

\section{FORMA DE CITAR}

Alegre-Agís E, Riccò I. Contribuciones literarias, biográficas y autoetnográficas a la antropología médica en España: el caso catalán. Salud Colectiva. 2017;13(2):279-293. doi: 10.18294/sc.2017.1203.

Recibido: 30 de octubre de 2016 | Versión final: 29 de enero de 2017 | Aprobado: 8 de febrero de 2017

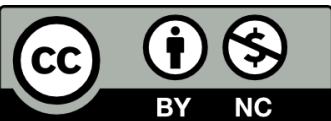

Este obra está bajo una licencia de Creative Commons Reconocimiento-NoComercial 4.0 Internacional. Reconocimiento - Permite copiar, distribuir y comunicar públicamente la obra. A cambio, se debe reconocer y citar al autor original. No Comercial - Esta obra no puede ser utilizada con finalidades comerciales, a menos que se obtenga el permiso. 